\title{
PENGEMBANGAN APLIKASI SISTEM INFORMASI AKADEMIK SDN 07 PAGI CIRACAS BERBASIS OBJEK
}

\author{
Rita Nuraini \\ Program Studi Teknik Informatika, Fakultas Teknik dan ilmu komputer, \\ Universitas Indraprasta PGRI \\ Jalan Raya Tengah No 80, Kelurahan Gedong, Pasar Rebo, Jakarta Timur \\ ritanuraini72779@gmail.com
}

\begin{abstract}
Abstrak
Sistem informasi akademik merupakan salah satu jenis dari sistem informasi yang dibuat untuk menangani hal-hal yang berkaitan dengan akademis (Riki et al., 2018). Permasalahan pada SDN 07 Pagi Ciracas ini adalah belum tersedianya sistem yang dapat memudahkan pihak sekolah untuk membuat rapor siswa yang lebih cepat dan efisien. Maka peneliti akan membangun sistem informasi yang tepat, jelas, dan efisien. Sistem Informasi Akademik ini menggunakan Sistem Informasi berbasis objek. Program ini dilihat dengan menggunakan perangkat lunak XAMPP, dan Netbeans IDE 8.0.2 serta database MYSQL, program ini berfungsi untuk megolah data tentang implementasi sistem informasi akademik pada SDN 07 Pagi Ciracas. Dengan adanya sistem informasi akademik pada SDN 07 Ciracas semua kegiatan akademik terutama membuat rapor siswa tidak lagi secara manual.
\end{abstract}

Kata Kunci: Sistem Informasi Akademik, Java, MySql

\begin{abstract}
Academic information systems are one type of information system created to handle matters related to academics (Riki et al., 2018). The problem at SDN 07 Pagi Ciracas is the unavailability of a system that can make it easier for schools to make student report cards faster and more efficient. Then the researcher will build an information system that is precise, clear, and efficient. This Academic Information System uses object-based Information Systems. Viewed using XAMPP software, and Netbeans IDE 8.0.2 as well as MYSQL databases, this program serves to create data about the implementation of academic information systems at SDN 07 Pagi Ciracas. With the academic information system in SDN 07 Ciracas all academic activities especially make student report cards no longer manually.
\end{abstract}

Keyword: Academic Information System, Java, MySql.

\section{PENDAHULUAN}

Perkembangan teknologi membuat beberapa pekerjaan bisa mudah dan cepat. Tidak hanya itu, perkembangan teknologi juga membuat pengolahan data lebih terstruktur dan mudah ditemukan bila dibutuhkan. Teknologi dapat digunakan dalam pendidikan dengan berbagai tema dan manfaat (Risdiansyah, 2017). Pendidikan adalah pembudayaan buah budi manusia yang beradab dan buah perjuangan manusia terhadap dua kekuatan yang selalu mengelilingi hidup manusia yaitu kodrat alam dan zaman atau masyarakat (Dewantara, 1994). Diketahui banyak perusahaan dan sekolah yang menggunakan sistem informasi secara komputerisasi sebagai pengelola perusahaan atau sekolah itu sendiri, sehingga dapat mudah mendapatkan informasi yang sesuai. Dengan adanya hal ini dapat memudahkan pekerjaan guru, sehingga dapat digunakan untuk membantu membuat penelitian hasil belajar siswa tiap semester di SDN 07 Pagi Ciracas . SDN 07 Pagi Ciracas didirikan pada tanggal 31 desember 1976. Sekolah Dasar Negeri 07 Ciracas pagi memiliki kode NPSN 20104355 dan kode NSS 101016404061. Pada tahun 2010, SDN Ciracas 07 pagi memiliki 199 pelajar laki-laki dan 153 pelajar perempuan, menjadikan jumlah keseluruhan murid sebanyak 352 orang. SDN 07 Ciracas memiliki sebanyak 13 orang guru. Rapor adalah laporan kemajuan belajar siswa atau peserta didik dalam kurun waktu satu semester (Oetomo, 2002). Saat ini SDN 07 Pagi Ciracas masih menggunakan pencatatan manual dalam membuat rapor siswa. Selain itu Jika terjadi kesalahan dalam penulisan rapor sulit untuk memperbaikinya dan dapat menyebabkan halhal lain yang tidak diinginkan yang menimbulkan resiko tinggi. Berdasarkan masalah yang sudah 
peneliti paparkan, maka dari itu peneliti mempunyai sebuah gagasan untuk membuat sebuah sistem yang nantinya akan sangat bermanfaat bagi SDN 07 Ciracas. Sistem adalah rangkaian dari dua atau lebih komponen-komponen yang saling berhubungan, yang berinteraksi untuk mencapai suatu tujuan (Romney \& Steinbart, 2015). Perancangan sistem merupakan tahap selanjutnya setelah analisa sistem, mendapatkan gambaran dengan jelas tentang apa yang akan dikerjakan. Pada analisa sistem maka dilanjutkan dengan memikirkan bagaimana membentuk sistem tersebut (Wijoyo \& Hermanto, 2020).

Tujuan penelitian ini adalah dengan adanya aplikasi ini diharapkan dapat memudahkan guru dalam mengisi nilai siswa dan dapat membantu menampilkan penilaian hasil belajar siswa secara real time dan terintegrasi.

\section{PENELITIAN YANG RELEVAN}

Penelitian yang dilakukan oleh (Karwandi, 2011) Hasil penelitian yang dilakukan oleh Endri Karwadi yang berjudul "Rancang Bangun Aplikasi E-Raport berbasis java" menghasilkan aplikasi berbasis desktop yang dapat memberikan sistem otomatisasi keputusan tentang penentuan ketuntasan belajar siswa yang mengacu hanya pada kurikulum yang berlaku. Perbedaan dari artikel di atas dengan artikel penulis terlihat pada hasil dari aplikasi yang dibuat, jika peneliti Endri Karwadi membuat penelitian hanya mengacu pada kurikulum yg berlaku seperti tujuan, materi, strategi, organisasi kurikulum dan evaluasi pembelajaran siswa seperti nilai mata pelajaran, nilai absensi dan nilai kepribadian siswa itu sendiri.

Hasil penelitian (Haryono, 2017) berjudul "Sistem Informasi Manajemen Rapor Siswa Bandar Lampung" penelitian ini membuat suatu sistem yang dapat menangani masalah tersebut. Sistem dibuat berbasis web agar data nilai yang diisi guru pengajar dapat langsung dilihat dan diterima oleh admin dan wali kelas. Sedangkan dari artikel penulis mengacu dan terfokus pada data siswa serta guru, nilai-nilai per mata pelajaran siswa, nilai absensi serta nilai kepribadian siswa yang dibuat dengan aplikasi program java desktop tidak dengan aplikasi program berbasis web.

Hasil penelitian (Prabowo \& Agustina, 2017) yang berjudul "perancangan sistem informasi pengolahan nilai rapor berbasis web SMK Negeri 1 purworejo" menyatakan bahwa SMK Negeri 1 Purworejo merupakan salah satu sekolah di Kabupaten Purworejo yang aktif dalam pemanfaatan teknologi informasi baik dalam kegiatan belajar mengajar maupun pada proses administrasi sekolah. Terbukti dengan sudah digunakannya beberapa sistem informasi pendukung kegiatan persekolahan seperti sistem pembelajaran online bagi siswa dan sistem informasi manajemen perpustakaan. Fakta tersebut didukung pula oleh masyarakat akademiknya yang sudah akrab dengan komputer maupun teknologi informasi lainnya. Namun belum tersedianya sistem informasi yang sesuai dengan kurikulum yang berlaku untuk membantu dalam penyusunan rapor siswa menyebabkan masih adanya beberapa kekurangan dalam kegiatan penyusunan rapor seperti kurang efektifnya pekerjaan, kelambatan proses penyusunan, hingga banyaknya waktu dan biaya yang dibutuhkan. Perbedaan dari artikel diatas dengan artikel penulis terlihat dari aplikasi yang dibuat, artikel diatas menggunakan aplikasi berbasis web sedangkan pada artikel penulis menggunakan aplikasi berbasis java dekstop.

\section{METODE PENELITIAN}

Dalam penelitian ini dilakukan metode Research and Development (R\&D) merupakan metode penelitian yang digunakan untuk menghasilkan produk tertentu dan menguji keefektifan produk tersebut (Nugroho, 2013). Dalam bidang pendidikan, penelitian dan pengembangan atau Research and Development (R\&D), merupakan metode penelitian yang digunakan untuk mengembangkan atau memvalidasi produk-produk yang digunakan dalam pendidikan dan pembelajaran. Dari uraian tersebut maka dapat ditarik kesimpulan bahwa Research and Development adalah metode penelitian yang bertujuan untuk menghasilkan produk-produk yang digunakan dalam pendidikan dan pembelajaran. Dari uraian tersebut maka dapat ditarik kesimpulan bahwa Research and Development adalah metode penelitian yang bertujuan untuk menghasilkan produk-produk tertentu serta menguji validitas dan keefektifan produk tersebut dalam 
penerapannya. Masalah di atas menimbulkan banyak pertanyaan dalam pikiran penulis untuk mengetahui bagaimana konsep penelitian R\&D dalam bidang pendidikan. Oleh karena itu, penulis tertarik untuk mengadakan penelitian tentang konsep penelitian R\&D dalam bidang pendidikan. Fokus penelitian ini adalah konsep penelitian $R \& D$ dalam bidang pendidikan yang dirinci menjadi lima subfokus, yaitu (1) karakteristik penelitian R\&D dalam bidang pendidikan, (2) langkahlangkah penelitian R\&D dalam bidang pendidikan, (3) topik penelitian R\&D dalam bidang pendidikan, (4) contoh judul penelitian R\&D dalam bidang pendidikan, dan (5) sistematika laporan hasil penelitian R\&D dalam bidang pendidikan (Hanafi, 2017).

\section{HASIL DAN PEMBAHASAN}

Setelah di analisa ada beberapa kelemahan dari sistem informasi akademik yang sedang berjalan, diantaranya:

1. dalam pembuatan nilai rapor masih manual.

2. hilangnya sebuah rapor siswa karena kelalaian pihak sekolah.

3. terjadinya hal-hal lain yang tidak diinginkan yang menimbulkan resiko tinggi.

4. jika terjadi kesalahan dalam penulisan rapor sulit untuk memperbaikinya.

5. dalam rekapitulasi data banyak mengalami kesulitan atau rawan.

\section{Alternatif Penyeselesaian Masalah}

Setelah menganalisa dan mengevaluasi sistem yang sedang berjalan, maka sebagai tindak lanjut bagi penyelesaian masalah maka jalan alternatifnya adalah:

1. perlu dibuat aplikasi sistem informasi perancangan sistem yang terkomputerisasi dan terintegrasi agar pembuatan rapor dapat digunakan dengan maksimal serta dapat memudahkan pihak sekolah memberikan hasil akhir kegiatan belajar siswa.

2. menyimpan data sekolah ke dalam bentuk database sehingga mudah dalam pengolahannya.

3. cetak hasil rapor siswa dengan memanggil database dengan menggunakan pemograman java.

\section{Aturan sistem yang diusulkan}

Aturan sistem dalam sistem akademik yang diusulkan pada SDN 07 Pagi Ciracas adalah sebagai berikut:

1. untuk membuat aplikasi sistem informasi akademik ini perlu adanya izin dari pihak sekolah untuk mengetahui apakah pihak sekolah bersedia adanya aplikasi ini atau tidak.

2. kemudian, setelah pihak sekolah mengizinkan aplikasi dibuat dan dijalankan sesuai bagaimana yang sudah direncanakan.

3. siapkan program java seperti xammp dan netbeans untuk menjalankan program ini.

4. setelah aplikasi dibuat ada 3 pihak yang dapat masuk ke dalam aplikasi ini yaitu admin, guru serta walikelas.

5. untuk menjalankan aplikasi ini masing-masing pihak mempunyai hak akses mempunyai email dan password untuk masuk ke dalam program tersebut.

6. didalam aplikasi ini yang dapat mencetak rapor hanya walikelas saja.

\section{Use case diagram}

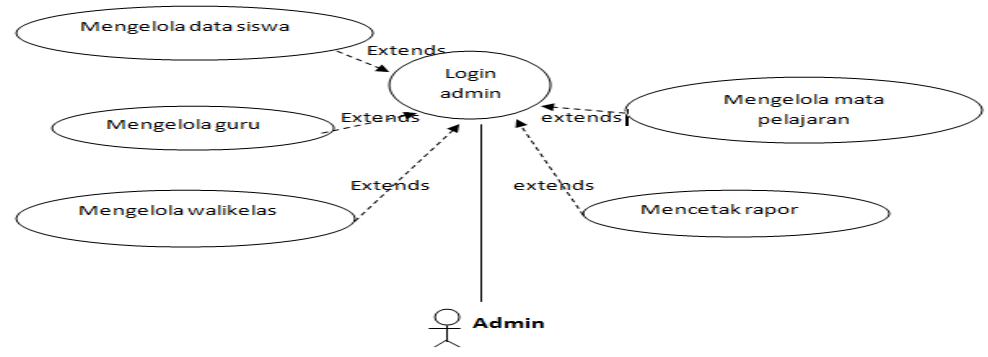

Gambar 1. Use case diagram admin 


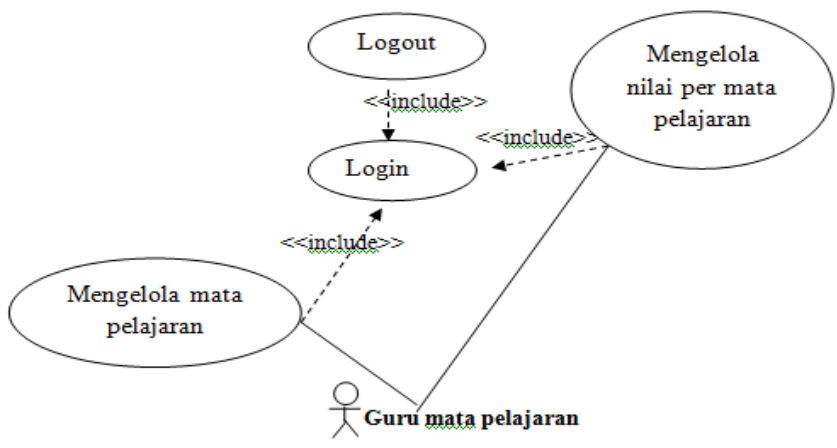

Gambar 2. Use case diagram mata pelajaran

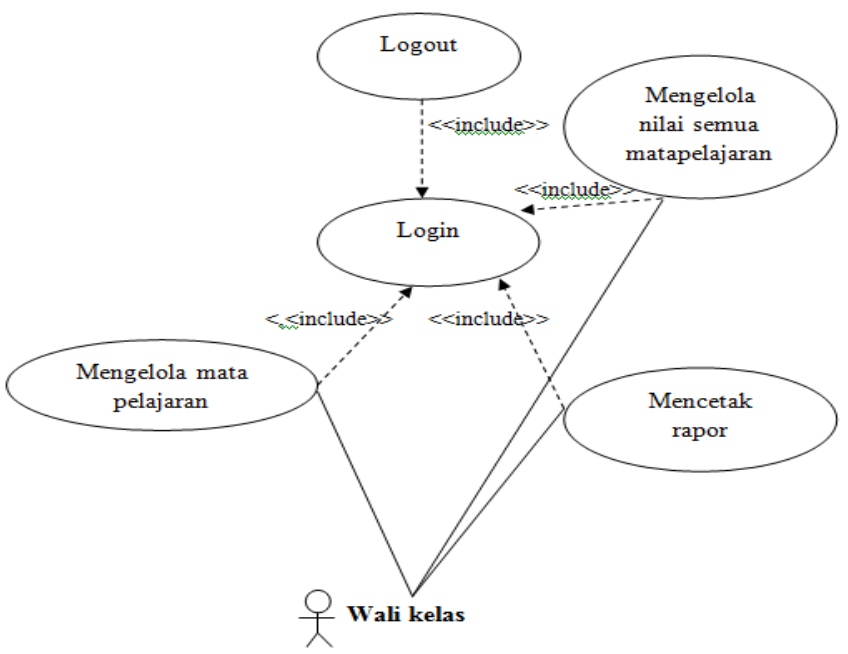

Gambar 3. Use case diagram walikelas

\section{Tampilan Aplikasi}

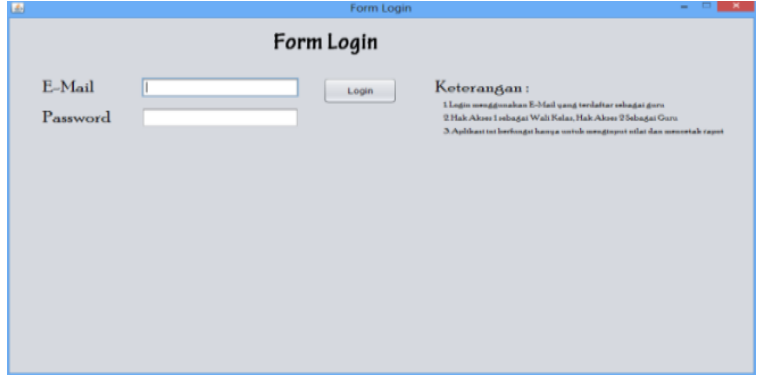

Gambar 4. Tampilan form login

Gambar diatas adalah merupakan form login yang digunakan untuk melakukan akses ke menu utama. Dan jika logout akan kembali ke form ini 


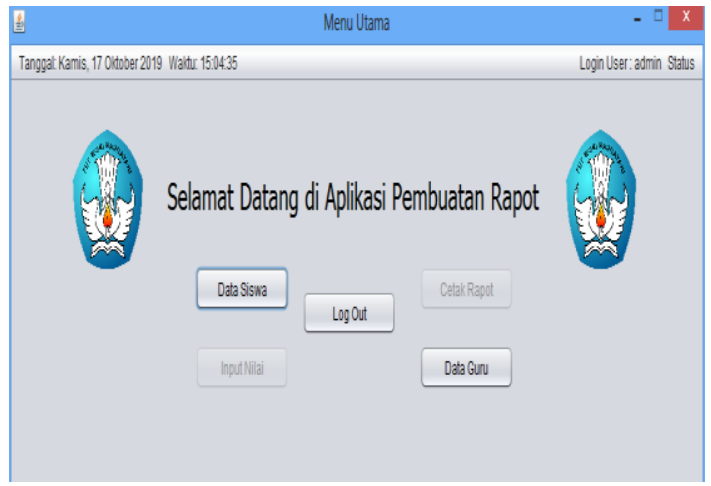

Gambar 5. Tampilan menu utama admin

Gambar diatas merupakan Menu Utama admin. Setelah berhasil login akan masuk ke menu utama . dalam menu utama admin terdapat beberapa menu diantaranya menu data siswa, menu data guru, dan logout.

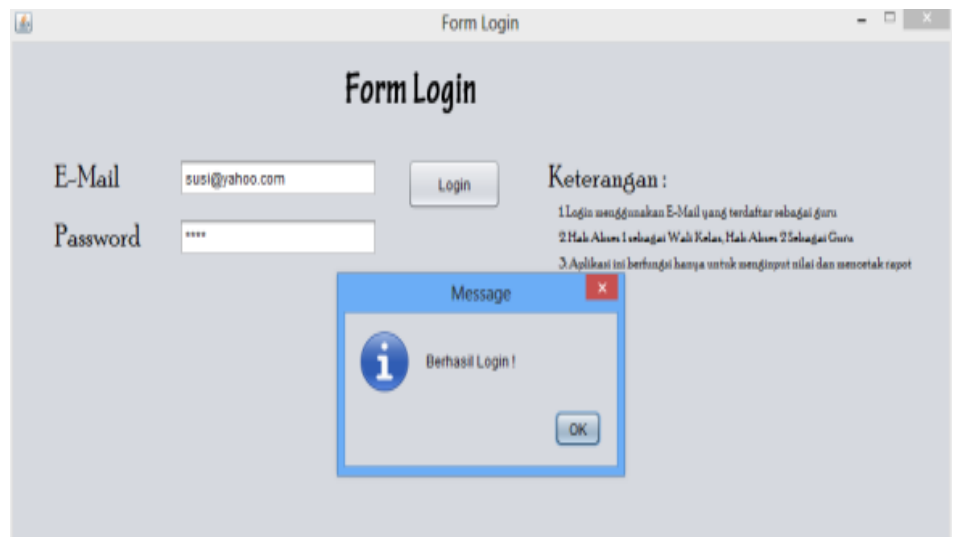

Gambar 6. Tampilan login guru

Gambar diatas merupakan tampilan form login guru yang sudah ditulis email dan password yang sudah dimiliki guru tersebut. 
Jurnal Riset dan Aplikasi Mahasiswa Informatika (JRAMI)

Vol Q2 No 04 Tahun Z02I

e-ISSN : 2715-8756

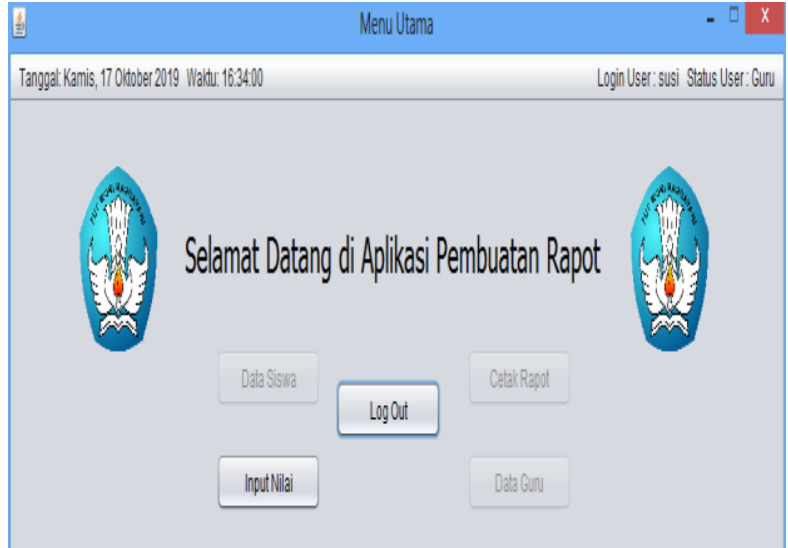

Gambar 7. Tampilan menu utama user guru

Gambar diatas merupakan tampilan menu utama user guru, dalam menu utama user guru terdapat menu input nilai, dan logout.

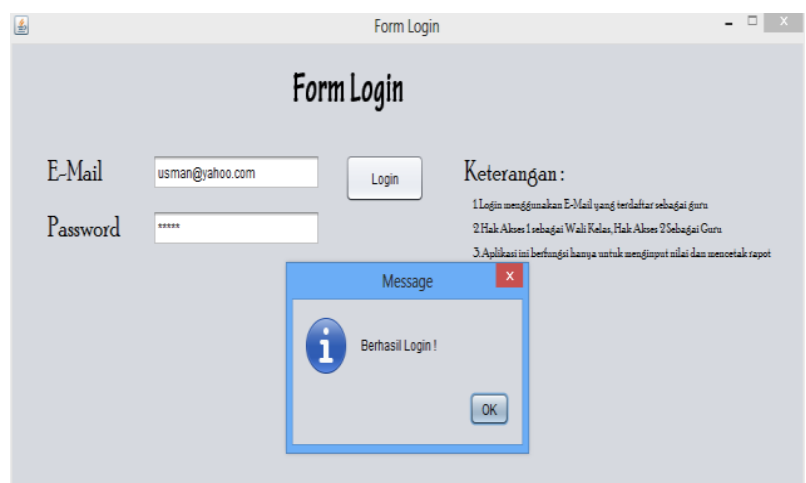

Gambar 8. Tampilan login walikelas

Gambar diatas merupakan tampilan form login user walikelas yang sudah ditulis email dan password yang sudah dimiliki walikelas tersebut.

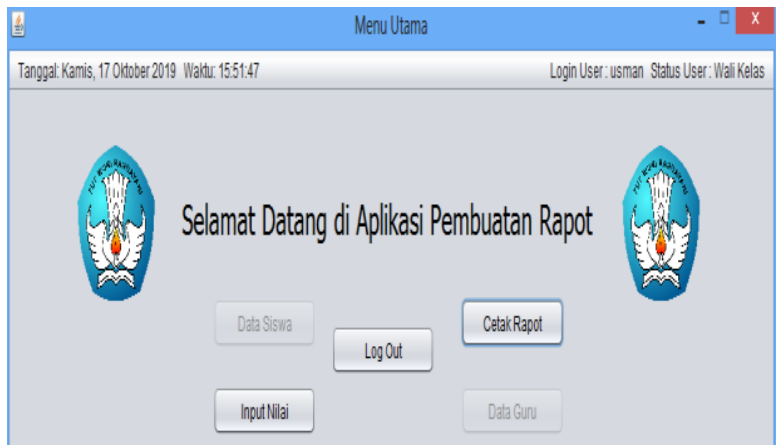

Gambar 9. Tampilan menu utama user walikelas 
Gambar diatas merupakan tampilan menu utama user walikelas. Dalam menu utama user guru terdapat input nilai, logout, dan cetak rapor.

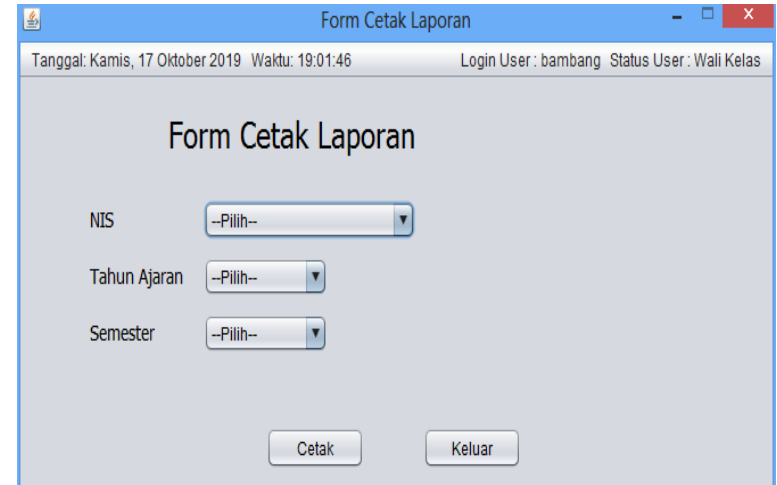

Gambar 10. Tampilan form cetak laporan

Gambar diatas merupakan tampilan menu cetak rapor pada user walikelas. Dalam menu form cetak laporan terdapat NIS, tahun ajaran, dan semester.

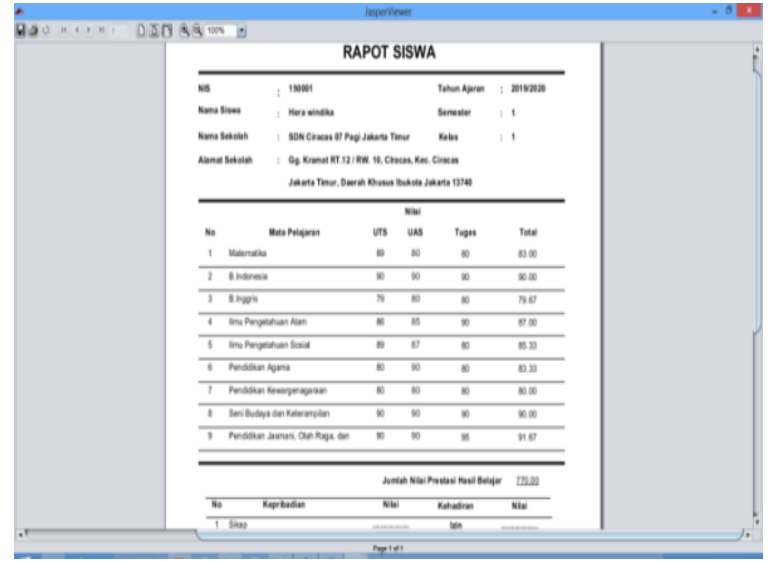

Gambar 11. Tampilan hasil rapor siswa

Gambar diatas merupakan tampilan setelah klik cetak pada form cetak laporan. Tampilan ini adalah hasil akhir pada sistem ini.

\section{SIMPULAN}

Dengan dibuatnya Pengembangan Aplikasi Sistem Informasi Akademik SDN 07 Pagi Ciracas, semua kegiatan yang berhubungan dengan informasi pengelolaan data siswa, pengelolaan data guru, pengelolaan nilai, dan cetak rapor tidak lagi secara manual. Dengan adanya peralatan komputer dapat membantu. Peneliti memiliki kesimpulan dengan menggunakan aplikasi yang dibuat ini dapat memudahkan pihak sekolah serta keamanan lebih terjamin, dan dapat dilakukan dengan cepat, tepat, dan efesien. Memudahkan pihak sekolah mengontrol data yang ada didalam database. 
Jurnal Riset dan Aplikasi Mahasiswa Informatika (JRAMI)

Vol Q2 No 04 Tahun Z0Z1

e-ISSN : $2715-8756$

\section{DAFTAR PUSTAKA}

Hanafi. (2017). Konsep Penelitian $R \&$ D Dalam Bidang Pendidikan. Saintifika Islamica: Jurnal Kajian Keislaman, 4(2), $129-150$.

Haryono, M. H. (2017). Sistem Informasi Pengisian Nilai Dan Pencetakan Rapor Otomatis Pada SMA Al Kautsar Bandar Lampung.

Dewantara I. (1994). PENGERTIAN PENDIDIKAN. https://asiswanto.net/?page_id=305

Karwandi, E. (2011). RANCANG BANGUN APLIKASI E-RAPORT BERBASIS JAVA PADA SMK MARDHOTULLAH PLAYEN. In International Working Group on the Diabetic Foot. International Consensus on the Diabetic Foot \& Practical and Specific Guidelines on the Management and Prevention of the Diabetic Foot. Launched at the 6th International Symposium on the Diabetic Foot, May (Vol. 11, Issue 2). https://doi.org/10.16194/j.cnki.31$1059 / g 4.2011 .07 .016$

Nugroho, M. B. (2013). BAB III METODE PENELITIAN. In Journal of Chemical Information and Modeling (Vol. 53, Issue 9). https://doi.org/10.1017/CBO9781107415324.004

Oetomo. (2002). konsep dasar rapor.

Prabowo, W. S., \& Agustina, C. (2017). Perancangan Sistem Informasi Pengolahan Nilai Rapor Berbasis Web Pada SMK Negeri 1 Purworejo. Jurnal Khatulistiwa Informatika.

Riki, Sari, A. O., \& Indriani3, K. (2018). Rancang Bangun Sistem Informasi Akademik Sekolah Berbasis Web Pada Smp Plus Al-Ijtihad 2 Kutabaru Tangerang. Jurnal Ilmu Pengetahuan Dan Teknologi Komputer.

Risdiansyah, D. (2017). Perancangan Sistem Informasi Bimbingan Konseling Berbasis Desktop pada SMA Kemala Bhayangkari 1 Kubu Raya Deni. Khatulistiwa Informatika.

Romney, M. B., \& Steinbart, P. J. (2015). Pengertian sistem menurut Marshall B Romney dan Paul John Steinbart. In Sistem Informasi Akuntansi.

Wijoyo, A. C., \& Hermanto, D. (2020). Analisis dan Perancangan Sistem Informasi Inventory pada PT Insan Data Permata. Jurnal Riset Dan Aplikasi Mahasiswa Informatika (JRAMI), 1(02), $165-170$. https://doi.org/10.30998/jrami.v1i02.231 